\title{
The Role and Value of Out-of-School Environments in Science Education for 21st Century Skills
}

\author{
Thomas Bjørneboe Berg ${ }^{1 * t}$, Marianne Achiam ${ }^{2 \dagger}$, Kristian Mandrup Poulsen ${ }^{1}$, \\ Lene Bech Sanderhoff ${ }^{3}$ and Anders P. Tøttrup ${ }^{4}$
}

${ }^{1}$ Naturama, Museum of Natural History, Svendborg, Denmark, ${ }^{2}$ Department of Science Education, University of Copenhagen, Copenhagen, Denmark, ${ }^{3}$ Geo and Bio Science Center Syd, Faaborg Gymnasium, Faaborg, Denmark, ${ }^{4}$ Research and Collections, Natural History Museum of Denmark, University of Copenhagen, Copenhagen, Denmark

\section{OPEN ACCESS}

Edited by:

Chantal Lise Barriault, Laurentian University, Canada

Reviewed by: Michael Reiss, University College London, United Kingdom Jon Mason,

Charles Darwin University, Australia

*Correspondence: Thomas Bjørneboe Berg thomas@naturama.dk

${ }^{\dagger}$ These authors have contributed equally to this work and share first authorship

Specialty section: This article was submitted to STEM Education, a section of the journal Frontiers in Education

Received: 01 March 2021 Accepted: 22 April 2021 Published: 07 May 2021

Citation:

Berg TB, Achiam M, Poulsen KM, Sanderhoff LB and Tøttrup AP (2021) The Role and Value of Out-of-School Environments in Science Education for 21st Century Skills.

Front. Educ. 6:674541. doi: 10.3389/feduc.2021.674541
The global "wicked" problems we face in the 21st century call for 21 st century competencies. The formal education system is hard pressed to foster these competencies within the science curriculum. Accordingly, we argue that out-of-school science education can function as an alternative pathway to 21 st century competencies among learners. We present four distinct community case stories on teaching science in out-of-school environments and link them to a number of key challenges linked to achieving 21st century competencies. Natural history museums have been the foundation of science for four centuries and have served as the basis upon which nomenclature of all living species and the concept of evolution has been developed, hence our first case takes place within this frame. Without fieldwork natural history museums would not have any collections and Case 2 takes us out there where it all begins. Humans affect the entire globe and all living matters. Case 3 tells the story of how waste becomes authentic and debatable during a visit to a wastewater plant. Finally, new technologies in the service of natural science is the scope for Case 4 where students collect and analyze their samples of eDNA at university lab facilities in collaboration with scientists, generating valuable real data for research projects. We summarize by discussing how, to meet the challenges of the future, there is a need to strengthen the content and context of curriculums as well as the skills of the learners within natural sciences. The four cases address different themes and skills connected to the highly complex problems like climate change and loss of biodiversity, that may be difficult to comprehend for the greater public but are urgent to teach the adults of tomorrow.

Keywords: science education, 21st century skills, out of school environments, informal education, science engagement, participatory science

\section{INTRODUCTION}

As humanity faces a range of economic, environmental, and social "wicked" problems that are increasing in severity, attention turns to education as a crucial means of preparing us for a more sustainable future (Holfelder, 2019). The uncertainty of the 21st century calls for 21 st century skills, i.e., problem solving, critical thinking, communication, collaboration, and self-management [National Research Council (NRC), 2012; Organization for Economic Co-operation and Development (OECD), 2018]-cross-cutting competencies that do not always sit comfortably 
within the boundaries of formal curricula and subjects, nor within the rules and norms that govern practice in schools and classrooms. Specifically, the OECD Education 2030 Working Group identified five common challenges to the formal school system that hinder or constrain the translation of these competencies into education practice: 1) Curriculum overload, 2) Time lag between curriculum reform and implementation, 3) Quality of content, 4) Lack of equity, and 5) Non-alignment with existing teaching and assessment practices. Even though efforts are being made to address these challenges by gradually changing curricula and education systems in different countries (OECD, 2018), we suggest here that out-of-school science education offers an alternative pathway toward promoting 21 st century skills.

By out-of-school science education environments we are referring not just to institutions such as museums and science centers, but also to fieldwork localities, industry, research laboratories or community activities. These environments exist independently of the school system, and accordingly, are not governed by the rules of that system. In the following we will discuss and substantiate how experiences in out-of-school science education environments have renewed relevance in terms of promoting the global transition to sustainability (cf. Xanthoudaki, 2015; Achiam et al., 2021). First, we briefly discuss the challenges identified by OECD Education 2030 of making 21st century competencies actionable in school science and outline how out-of-school contexts might overcome these challenges. Then, we provide four case studies that exemplify our arguments in different and complementary ways. Finally, we discuss the implications of our thesis for science education outside school.

\section{Operationalizing 21st Century Competencies}

As scientific knowledge and know-how accumulate, school science curricula are increasingly suffering from overload. This presents an important challenge to making 21st century competencies actionable, because students do not have the time to master the relevant disciplinary knowledge (OECD, 2018). A solution that has often been applied to this challenge is problem-based learning, an instructional method that employs complex, real-world problems to structure learners' self-guided and collaborative identification and acquisition of relevant and operational knowledge (Hmelo-Silver, 2004; Gilbert et al., 2011). Well-designed problems guide learners to use relevant knowledge and skills to infer fundamental principles and procedures for themselves (Prince and Felder, 2006), rather than requiring them to sift through an overloaded curriculum to determine what is applicable. In the following, we illustrate how out-of-school science environments (in particular Case 3, a wastewater treatment plant) are ideal settings for problem-based learning, because they are situated in society and in many cases deal directly with the tangible, real-life, often ill-structured problems of that society.

Another challenge to the operationalization of 21 st century skills in school is the time lag between the intentions of a curriculum and its implementation and impact (OECD, 2018).
This gap is caused by the delay from the publication of scholarly knowledge (whether related to science or science education) to its introduction in curricula and textbooks (cf. Quessada and Clément, 2007; Clément and Castéra, 2013). This delay is not present to the same degree in out-of-school science environments because they are often places of on-going scientific research, for instance museums or research laboratories. Accordingly, they have direct access to cutting-edge scientific knowledge and practice and can engage learners in this 'science in the making' rather than the "ready-made science" (cf. Latour, 1987) of the formal science curriculum. We suggest that because outside school, teaching is driven by current cases and problems that are not linked to formal textbooks, the problem of time lag between curriculum reform and implementation is alleviated here. In Case 4, we Illustrate how cutting-edge science motivates students to engage with science.

If the curriculum is overloaded and out of date, as discussed in the preceding, it is not difficult to imagine that learners will also perceive it as being of poor quality. This stands in the way of the acquisition of deeper understanding (OECD, 2018). We suggest that out-of-school science environments can help alleviate this problem by placing scientific material and ideas within an explicitly real-life context that is relevant to students from diverse backgrounds. Ideally, this context would require learners to reflect on their available knowledge in the context of authentic data and scientific methodology (Gilbert et al., 2011) and in doing so, answer the questions for themselves of "why do I have to know this?" and "will I ever use this again?" (Taasoobshirazi and Carr, 2008). We demonstrate the potential of learning in context in Cases 1 and 2 .

Although it is an important objective of science education to produce innovators, too often the benefits of social, economic, and technological innovations are unevenly distributed (OECD, 2018). Even though objectivity is an important part of the selfimage of the natural science disciplines (Reiss and Sprenger, 2017), research shows that science curricula may promote inequity by implicitly sanctioning certain identity performances among learners while discouraging others (Ulriksen, 2009). We suggest that out-of-school science environments can prompt constructive ruptures from the behavioral norms of the everyday science classroom, allowing learners to negotiate and challenge stereotypical "ways of doing" (Silfver, 2018). We argue that all the cases we present here have this potential, and we return to this point in the discussion.

Finally, the OECD Education 2030 Working Group (2018) pointed out that 21 st century competencies are not easily measurable with the assessment tools that are available to the science education community today (see also Dolin et al., 2018). This hinders the constructive alignment (cf. Biggs, 1996) between 21 st century curriculum objectives, instructional design, and assessment, thus constraining the successful implementation of teaching for 21 st century skills in schools. Although we are not suggesting here that out-of-school science education environments should become places of assessment, we agree with scholars who point out that assessment of competencies should focus more holistically on scientific practices prompted in authentic, real-life contexts (Rönnebeck et al., 2018; Ropohl et al., 
2018). Out-of-school environments might thus provide valuable input to research in what constitutes good practice in the assessment of 21st century skills, because they are neither overly focused on specific disciplinary skills, nor do they prompt completely generic competencies (cf. Nielsen et al., 2018).

There are a few basic components that must be addressed for students taking sciences classes. Science is all about describing what we see and to understand the linkages between the various boxes that make up the system that we are studying as well as the cause and effect of changes we observe within the system. Three basic questions must be addressed: 1) What is the problem or question we are aiming for to answer? 2) Why is it important or interesting? 3) How can we solve the problem or answer the question? Scientific methods are only valid if they can be reproduced by others, i.e., they need to be standardized.

\section{CASE 1: NATURAL HISTORY MUSEUM}

The first case we present takes place in a natural history museum, defined in general by the three museum "pillars" of collections, research and dissemination (NATHIST, 2013). Natural history museums reflect the ongoing practices, discourses, and ways of reasoning of natural history in order to understand the interconnectedness of living things and the environment (King and Achiam, 2017). Natural history collections-based research in museums has thus contributed to our understanding of several of the global problems we are facing, e.g., the biodiversity crisis or the global pandemic (Suarez and Tsutsui, 2004; McLean et al., 2016). In the following, we illustrate how this case addresses the curriculum challenge identified by OECD (2018) of poor-quality curriculum.

\section{Setting the Scene}

Naturama is one of three classical museums of natural history in Denmark. In 2017 Naturama was part of an interdisciplinary education project with the Department of Mathematics and Computer Science at the University of Southern Denmark. For many students, mathematics can be difficult (Salout et al., 2013; Murphy, 2017), hence the idea was to teach mathematics by addressing real-life examples with appealing hands-on activities. These examples were selected to help learners grasp how mathematics can support new insights as well as an understanding of the world around them.

The aim was to use the natural history setting and narrative to frame the teaching of mathematics using museum specimens. The basic mathematical tools in the present case story are measurements, statistical descriptions of the data and statistical analytical tools to test for differences between subsets of data collected during the event. The project consisted of four independent visits that focused on 1) Evolution, taxonomy, variation, and scientific measurements; 2) Comparative physiology; 3) Sexology and reproductive strategies; 4) Population biology, demography, and population estimates. Here, we focus on the first visit. Without careful studies of museum collections, Linné, Darwin, Wallace and others would not have been able to develop taxonomy and the theory of evolution, upon which the understanding builds of species differentiation and their adaptations to specific habitats and its biodiversity. The first visit thus embodies content that is specific and essential for natural history museums.

\section{Case Description}

Evolution explains the origin of today's life on earth and is overwhelmingly accepted in the Scandinavian countries (including Iceland) and in most European countries (Miller et al., 2006); however, a large part of the world's population does not see evolution as the mechanism behind speciation. In fact, roughly a third of all Americans believe that humans have existed in their present form since the beginning of time (Berkman et al., 2008; Cooperman et al., 2019). Hence teaching evolution is highly relevant on a global scale.

The visit by the high school class begins with an introduction to the mechanisms behind evolution. Then, a guided tour in the exhibition allows the learners to engage with the various animal species on display and their evolutionary links. In the main part of the visit, learners engage in hands-on measurements and nonmetric analyses of specimens from the museum's collections. The exercise also illustrates how data collection is affected by the observer, and how mathematics is required as a scientific tool to handle these variations.

A collection of mink skulls (Mustela lutreola) is examined using calipers. Several students take the same measurements (e.g., length of skull) which produces the inevitable variation in data obtained by different examiners on the same specimen; this variation serves as a basis for calculating mean values and variance. The objective is for the student to be able to test whether there are significant differences in the precision of specific measurements taken, and whether some measurements have a smaller variance than others, hence being more robust as characters. As the skulls are sorted by sex, sexual dimorphism can be examined as well as relations between related measurements e.g., length vs width.

Another way of describing and analyzing differences between individuals is to register, count or score nonmetric variables and symmetry. Nonmetric variables are recorded without the use of e.g., a caliper but can be e.g., the number and placement of foramen (nerve holes) on the skull or a subjective ranked score of asymmetry. These are phenotypic characters reflecting the genetic variation of a trait. Symmetry has in some studies been regarded as an advantageous trait among males in the competition for females and hence their fitness (Møller, 1992; Møller and Pomiankowski, 1993). For this exercise students are presented with a collection of male roe deer skulls with antlers. The left and right antler are scored for their asymmetry, and the volume (metric variable) of the antlers is measured by submerging the antler (from tip to the base) in a water container with volume markings. In the discussions of these examinations, factors affecting the size and shape of the antlers are considered, including the age of the individual and the quality and calcium content of the food. Asymmetry is not just affected by genes; injuries acquired during the growth of the antlers can also deform them and cause asymmetry. Accordingly, there may be annual variations within a single individual. 


\section{What Have We Learned?}

This exercise presents the learners how to look for similarities among different species in the exhibition and to group them within taxonomic terms. As a scientific tool measurements are important to describe a species, but not every character is suitable to measure for descriptive purposes. By examining and discussing the underlying variables affecting their obtained data the students gain a valuable mathematics-based perspective on how to approach scientific data.

\section{CASE 2: FIELDWORK}

Field work is the study of the environment that takes place outdoors and uses the environment as a learning resource (Scott et al., 2006). It studies the complex of variables that are involved in the interrelationships between living things and their environment and offers a genuine open-ended context for scientifically authentic work, because neither learners nor educators know the answers to the questions that it prompts (Lock, 1998). Field work can encompass inquiry at many different levels, from large-scale composition and characteristics of biomes to the small-scale habitat of, for instance, cow dung situated in the different microhabitats of a shady forest or a sunny heathland. In the following, we illustrate how Case 2 can help counteract the experience of a poor-quality science curriculum by providing learners with an authentic, problem-based context.

\section{Setting the Scene}

Geo and Bio Science Center South is an initiative that offers free high-quality education in suitable nature areas with the aim to increase students' interest in the natural sciences. The Center offers a variety of different interdisciplinary courses on biodiversity, ecology, evolution, sustainable food production, climate change, geoscience, and landscaping, aimed at students from middle school to high school. Within each topic, different themes or exercises are offered as "building blocks", and it is common practice to mix exercises from different courses to match the visiting teacher's wishes for the day and the curriculum.

The programs are conducted outdoors, in nature, to prompt participants to follow their own lines of inquiry, and to provide an authentic real-life setting for those inquiries. For instance, in the case of the biodiversity program that we discuss in the following, different forest plots give participants the opportunity to infer what factors influence biodiversity by assessing the biodiversity within these plots. For instance, forests can play an important role in storing carbon dioxide as well as securing a high biodiversity, but these aims may not necessarily go hand in hand as forests may be used to produce timber for e.g., houses, which will store carbon dioxide on the long term, but support a less rich biodiversity. In this way, participants are prompted to qualify their understanding of the present biodiversity crisis.

\section{Case Description}

After a brief introduction to the purpose and program of the day the students are taken on a walk in the forest to monoculture tree plots, e.g., young and older beech plots, and conifer plots. They qualitatively examine the biodiversity of the trees by collecting as many different leaves as possible within five minutes. All leaves are then lined up and divided into functional groups, and the total number of species is counted. The result is usually $8-10$ species.

The next exercise quantifies the invertebrate diversity on the forest floor. As the method has to be standardized in order for comparison, we discuss the various methods available depending on the specific scientific question raised by the teacher and the composition of the study plot. The students are responsible for choosing their own sampling site within the well-defined monoculture in focus. Using a simple guide and illustrated key, the students can identify most of the invertebrates, at least to the level of order. The number of different species and "species groups" is noted.

Finally, to illustrate that different types of habitats, even those in close proximity to each other, can have remarkable differences in biodiversity, the exercise moves further into the woods to a patch of wild forest. Here, the exact same surveys are carried out. The biodiversity of trees and bushes in the wild forest plot is usually $15-20$ species, and the number of different invertebrates is also much higher. These different forest plots clearly illustrate the concept and link between biodiversity and habitat heterogeneity. In addition, the importance of variation in structure, ages and plant species for the insects inhabiting the forest becomes evident. The students are asked to discuss and explain how this correlates with their results, and obvious sources of error are discussed to help the students reflect on the method used and qualify their understanding of the gained results.

\section{What Have We Learned?}

At the end of the program, the students discuss approaches to the challenges of climate change and the biodiversity crisis. Most of the students usually agree on the needs for reducing the area of agricultural land, increasing the area of forests, particularly wild forests. At this point they might also discuss concrete actions that they themselves can carry out to take ownership and responsibility to meet the challenges of the future.

\section{CASE 3: WASTEWATER TREATMENT PLANT}

The third case is set at a working wastewater treatment plant and exemplifies an industry-based science education situation. Unlike schools who are constrained by curriculum requirements, industry-based science institutions represent applied, real-life science that does not need justification. Research shows that the industrial context can indeed provide learners with compelling authentic problems (Erhart et al., 2016) that motivate them to engage and ultimately envision science as a career pathway (Porter et al., 2006). In the following, we show how Case 3 provides an authentic framing of real-life science problems, whilst sidestepping problems of an outdated curriculum. 


\section{Setting the Scene}

Being alive always creates waste of some sort. But human waste products have changed the course of life on Earth. Waste products and pollution that originate from all the various goods from e.g., clothes, smartphones to space rockets can be hard to grasp, but focusing on daily waste that we all process and get rid of through the sewer system can be very present and a real eye opener.

In Denmark, wastewater is treated mechanically, biologically or chemically at more than 825 wastewater facilities across the country. These are owned by the municipalities but are driven as private companies. The primary focus is to clean wastewater and secondly to produce energy from the waste products. Some of these companies additionally offer guided tours of their facilities as well as topical hands-on activities for school groups. Biofos is such a company and offers programs to involve students from middle school to high school in the interdisciplinary science behind the treatment of wastewater.

\section{Case Description}

The visit starts with an indoors presentation on how the sewer systems and treatment plant are connected. It describes the different steps in the treatment process, using live microscope images of bacteria and microorganisms that support the cleaning of the water. It explains how bacteria are crucial to the functioning of our bodies, in food production, and in the degradation of biological material. The setup enables the students to discuss the kind and amount of wastewater that they produce daily and explore the science behind wastewater treatment. A simple experiment shows the degradation of sugar by a mix of water, sugar, and yeast placed in a bottle with a balloon on top. The yeast decomposes sugar to water and carbon dioxide (and a small amount of alcohol). An advantage is that the students can easily reproduce the experiment in their own school laboratory, for instance for a school report.

Where the sewer system enters the facility, the color of the wastewater is dark brown, the smell is unpleasant, and occasionally some of the more solid waste products such as diapers or sanitary napkins are visible. Midway, the wastewater has a high concentration of bacteria, and the water looks viscous, almost like chocolate milk. The smell has diminished. At the last stop, the wastewater is clear and odorless and looks almost like drinking water.

\section{What Have We Learned?}

Prior to the visit, the attitude of many students is that wastewater is disgusting and smelly; indeed, this is also the reality they encounter upon their arrival. Their step-by-step experience of wastewater treatment confronts them with the magnitude of human waste (in the thousands of cubic metres!), and the volume and capacity of the treatment plant. They gain insights into how "wastewater" can be seen as a valuable resource, as most of the residual product is used to produce biogas and heat. These new insights allow students to have qualified discussions of how climate change and heavy rain in cities affect those cities, the treatment plants, and the infrastructure. A visit like this does not follow the curriculum of school subjects (e.g., physics, chemistry, or biology) but focuses on a real-life problem that transcends disciplines. This is the privilege of out of school service, and the feedback from students and teachers indicates that they appreciate the close link between theory and practice.

\section{CASE 4: DNA LABORATORY}

The final case presented here combines many of the features of the preceding three cases, namely a natural history museum framing, field work, and an authentic laboratory setting. However, what we wish to emphasize is the cutting-edge nature of the work that goes on in the program. Research suggests that an immersion into the continuous development of scientific knowledge is necessary in the formation of scientifically literate citizens; yet much science inside and outside schools is presented as objective and finished (Hine and Medvecky, 2015). In the following, we demonstrate how the close proximity between science research and science education in Case 4 allows learners to engage themselves in uncertain science in the making, thereby acquiring valuable experiences of scientific methodology and its implications.

\section{Setting the Scene}

All living organisms release DNA into their environment. This can be skin cells, hair, eggs, feces, bones, etc. Such DNA is termed environmental DNA (eDNA) and detecting it in the environment is a novel non-invasive method of evaluating the presence of a species. Using eDNA has over the past couple of years been widely implemented in biodiversity surveillance projects across the world. The invisible DNA is detected using molecular "fishhooks" called primers. Primers are sequences of DNA which target specific species.

\section{Case Description}

The Natural History Museum of Denmark (NHMD) initiated a citizen science project in 2012 as a recurring opportunity for high-school students. The project, DNA and Life, creates a learning environment where high-school students work directly with researchers in detecting species using a cuttingedge eDNA research method. While students contribute water samples, they themselves collect from their local areas, they engage in authentic collaboration (cf. Bonney et al., 2009; Sandahl and Tøttrup, 2020) with researchers in the production and analysis of data to find answers to scientific questions (cf. Irwin, 1995) that can be used in species management.

Specifically, the objective of DNA and Life was to engage highschool students in hands-on testing of eDNA assays for environmental monitoring of freshwater and marine organisms in Denmark. The project aimed to increase highschool students' knowledge about the eDNA method; however, the main focus was to enhance students' understanding of the scientific process and in particular, their understanding of science in the making. However, another factor that gradually became apparent was how meeting and collaborating with real scientists was highly motivating for the students (Sheard et al., 2018). 
DNA and Life allows students to experience the full range of scientific settings, from field work to the laboratory. They can thus follow the scientific process from the macroscopic habitats of living animals to sub-microscopic data observed through advanced methods. In the first step the students choose a local location that they find relevant and interesting. They collect a sample from this location, using a field kit sent to their school containing materials and instructions on handling eDNA. In the second step, the sample is sent to the NHMD laboratory in Copenhagen where it is prepared by technicians. In the third step, students visit NHMD to work with their own sample in an authentic laboratory. Here, the students amplify DNA from specific targeted species. The study design includes three kinds of samples: Two known control samples and one unknown (the students' sample). Using this approach, the project can deliver high quality data based on the analyses of non-professional highschool students.

\section{What Have We Learned?}

Evaluations of DNA and Life show that high school students can engage with the eDNA method, and that they generate results that can be used to monitor aquatic species. The students' cumulative success rate was high, but individual analyses often failed. We argue that both kinds of outcomes are important for understanding science in the making; certainly, students learned from the group discussions of both successes and failures following the laboratory work. In fact, the project design facilitated these discussions by including the testing of both control and intervention samples, even if the primary reason for this was to achieve research quality data. That the data resulting from their work was used for subsequent research and species management was another motivating learning outcome for the students.

\section{DISCUSSION}

We have offered our thoughts on how out-of-school science education can help learners acquire 21st century skills. Even so, there is nothing new about 21 st century skills; what is new is perhaps the extent to which a rapidly changing world requires these skills. Pressing wicked problems such as climate disruption, biodiversity loss, deforestation and pollution gives a new sense of urgency to science education, which must provide actionable understanding of natural processes, links between species, and evolutionary mechanisms. This understanding is only enriched by knowledge and skills acquired in other contexts and thus emphasizes the value of the interplay between the science learning contexts.

We have argued the importance of out-of-school experiences for achieving 21st century skills and ultimately, contributing toward a more sustainable future. In particular, we have argued that out of school science education addresses the challenges identified by the OECD Education Working Group (2018): We claim that out of school science education can facilitate a more comprehensive understanding of the world around us and of why knowledge is crucial in making the right decisions. In the following, we discuss these points in further detail.

As science communicators and educators, we have witnessed firsthand how constraints and requirements from broader society have led to science curriculum overloading. The OECD (2018) recommendation of shifting the focus from "more hours of learning" to "more quality learning time" speaks directly to the cases presented here, which collectively offer high-quality learning driven by immersive hands-on activities, authentic situations, and "real life challenges and questions. Defining and implementing a new curriculum takes time. As discussed in the preceding, the process is constrained by a number of societal requirements, and thus risks rendering the new curriculum out of phase with rapidly developing socioscientific issues and their solutions. Each of the presented case stories included high priority content such as evolution, biodiversity, pollution, reuse of bioresources, climate change and cutting-edge techniques like eDNA. At the same time, topics like evolution, pollution, climate change and DNA are all to be found within the complex wicked problems that contain the risk of non-specialists to be left in a limbo of disillusion. Thus, the OECD recommendations for the design of learning processes and situations should be challenging and enable deep thinking and reflection (OECD 2018). In this respect topics that are directly relatable to the students and their interests comprise the easiest path to their engagement. This is evidenced by movements such as Greta Thunberg's Fridays for Future, which clearly address a wicked problem that young people-the adults of tomorrow-are concerned about and demand solutions for.

The massive global problems we are facing drives home the point that all students should have equitable opportunities to acquire the basic skills of the 21 st century. Inequity may originate and manifest itself at many levels, and even within prosperous countries, access to high quality education varies based on gender, ethnicity, ability, region and socioeconomic status. We argue that out-of-school science education provides learners from across these spectrums with opportunities to escape the often gendered, raced, classed scripts of school science to negotiate new ways of interacting with science that are personally meaningful (Silfver, 2018; Nicolaisen and Achiam, 2020), and we believe further research would be able to document such negotiations in the four cases discussed here.

However, an alternative pathway to providing equitable outof-school science experiences, that has become apparent in the ongoing covid-19 pandemic and related travel restrictions, is the provision of virtual programs and visits. Virtual teaching cannot, of course, provide direct hands-on experiences, but have other strengths, for instance allowing learners to interact with otherwise non-accessible virtual objects and experiments (e.g., The Digital Atlas of Ancient Life, https:// www.digitalatlasofancientlife.org/), or linking up with scientists all over the world. Fielding et al. (2019) described several cases where students were connected to ongoing research, even to research vessels in the middle of an ocean. Wildlife conservation classes at the University of Southern Denmark have likewise 
brought international conservation specialists from South Africa and Australia into an out-of-classroom event at a Danish zoo, giving students the opportunity to interact with the first authors of their hand-out references via Zoom (February 25th, 2021, Dalia A. Conde, pers. com).

For many learning environments, curriculums are often tied to the same textbooks for many semesters as teachers may be faced with work overload. So maybe at the bottom of the wicked problem of how to create curiosity, motivation, inspiring engagement among learners in a stimulating quality driven learning space is linked to the authenticity of the themes and context taught.

\section{REFERENCES}

Berkman, M. B., Pacheco, J. S., and Plutzer, E. (2008). Evolution and Creationism in America's Classrooms: A National Portrait. Plos Biol. 6 (5), e124. doi:10.1371/ journal.pbio.0060124

Biggs, J. (1996). Enhancing Teaching through Constructive Alignment. High Educ. 32, 347-364. doi:10.1007/bf00138871

Bonney, R., Ballard, H., Jordan, R., McCallie, E., Philips, T., Shirk, J., et al. (2009). Public Participation in Scientific Research: Defining the Field and Assessing its Potential for Informal Science Education. Washington, DC: Center for the Advancement of Informal Science Education (CAISE).

Clément, P., and Castéra, J. (2013). "Multiple Representations of Human Genetics in Biology Textbooks," in Multiple Representations in Biological Education. Editors D. F. Treagust and C.-Y. Tsui (Dordrecht: Springer), 147-163. doi:10. 1007/978-94-007-4192-8_9

Cooperman, A., Smith, G. A., Funk, C., Mohamed, B., Schwadel, P., Alper, B. A., et al. (2019). The Evolution of Pew Research Center's Survey Questions about the Origins and Development of Life on Earth. Available at: https://www. pewforum.org/2019/02/06/the-evolution-of-pew-research-centers-surveyquestions-about-the-origins-and-development-of-life-on-earth/ (Accessed January 17, 2021).

Dolin, J., Bruun, J., Constantinou, C. P., Dillon, J., Jorde, D., and Labudde, P. (2018). "Policy Aspects: How to Change Practice and in what Direction," in Transforming Assessment Research: Recommendations for Future Research. Editors J. Dolin and R. Evans (Cham: Springer), 249-278. doi:10.1007/978-3-319-63248-3_10

Erhart, S. E., McCarrick, R. M., Lorigan, G. A., and Yezierski, E. J. (2016). Citrus Quality Control: An NMR/MRI Problem-Based Experiment. J. Chem. Educ. 93 (2), 335-339. doi:10.1021/acs.jchemed.5b00251

Fielding, S., Copley, J. T., and Mills, R. A. (2019). Exploring Our Oceans: Using the Global Classroom to Develop Ocean Literacy. Front. Mar. Sci. 6, 340. doi:10. 3389/fmars.2019.00340

Gilbert, J. K., Bulte, A. M. W., and Pilot, A. (2011). Concept Development and Transfer in Context-Based Science Education. Int. J. Sci. Edu. 33 (6), 817-837. doi:10.1080/09500693.2010.493185

Hine, A., and Medvecky, F. (2015). Unfinished Science in Museums: a Push for Critical Science Literacy. Jcom 14 (2), A04. doi:10.22323/2.14020204

Hmelo-Silver, C. E. (2004). Problem-based Learning: What and How Do Students Learn? Educ. Psychol. Rev. 16 (3), 235-266. doi:10.1023/B:EDPR.0000034022. 16470.f3

Holfelder, A.-K. (2019). Towards a Sustainable Future with Education? Sustain. Sci. 14 (4), 943-952. doi:10.1007/s11625-019-00682-z

Irwin, A. (1995). Citzen Science. A Study of People, Expertise and Sustainable Development. London: Routledge. doi:10.1093/0195086457.001.0001

OECD (2018). The Future We Want. The Future of Education and Skills: Education 2030. Editor J. Skovgaard. Available at: https://www.oecd.org/ education/2030/E2030\%20Position\%20Paper\%20(05.04.2018).pdf (Accessed January 21, 2021).

King, H., and Achiam, M. (2017). The Case for Natural History. Sci. Educ. 26 (1), 125-139. doi:10.1007/s11191-017-9880-8

Latour, B. (1987). Science in Action: How to Follow Scientists and Engineers through Society. Cambridge: Harvard University Press.

\section{DATA AVAILABILITY STATEMENT}

The original contributions presented in the study are included in the article/Supplementary Material, further inquiries can be directed to the corresponding author.

\section{AUTHOR CONTRIBUTIONS}

TB and MA designed the concept and outline of the manuscript. All authors wrote sections of the manuscript and contributed to the manuscript revision, read, and approved the submitted version.

Lock, R. (1998). Fieldwork in the Life Sciences. Int. J. Sci. Edu. 20 (6), 633-642. doi:10.1080/0950069980200602

M. Achiam, J. Dillon, and M. Glackin (2021). in Addressing Wicked Problems through Science Education. The Role of Out-Of-School Experineces (Cham: Springer).

McLean, B. S., Bell, K. C., Dunnum, J. L., Abrahamson, B., Colella, J. P., Deardorff, E. R., et al. (2016). Natural History Collections-Based Research: Progress, Promise, and Best Practices. J. Mammalogy 97 (1), 287-297. doi:10.1093/ jmammal/gyv178

Miller, J. D., Scott, E. C., and Okamoto, S. (2006). SCIENCE COMMUNICATION: Public Acceptance of Evolution. Science 313 (5788), 765-766. doi:10.1126/ science. 1126746

Møller, A. P. (1992). Female Swallow Preference for Symmetrical Male Sexual Ornaments. Nature 357 (6375), 238-240. doi:10.1038/357238a0

Møller, A. P., and Pomiankowski, A. (1993). Fluctuating Asymmetry and Sexual Selection. Genetica 89 (1), 267-279. doi:10.1007/BF02424520

Murphy, P. E. L. (2017). "Student Approaches to Learning, Conceptions of Mathematics, and Successful Outcomes in Learning Mathematics," in Success in Higher Education: Transitions to, within and from University. Editors L. N. Wood and Y. A. Breyer (Singapore: Springer), 75-93. doi:10. 1007/978-981-10-2791-8_5

NATHIST (2013). ICOM Code of Ethics for Natural History Museums. Available at: http://icomnatistethics.files.wordpress.com/2013/09/nathcode_ethics_en 1.pdf (Accessed October 6, 2020).

Nicolaisen, L. B., and Achiam, M. (2020). The Implied Visitor in a Planetarium Exhibition. Mus. Manag. Curatorship 35 (2), 143-159. doi:10.1080/09647775. 2019.1691637

Nielsen, J. A., Dolin, J., and Tidemand, S. (2018). “Transforming Assessment Research: Recommendations for Future Research," in Transforming Assessment through an Interplay between Practice, Policy and Research. Editors J. Dolin and R. Evans (Cham: Springer), 279-290. doi:10.1007/ 978-3-319-63248-3_11

NRC (2012). Education for Life and Work: Developing Transferable Knowledge and Skills in the 21st Century. Washington, DC: The National Academies Press.

Porter, C., Parvin, J., and Lee, J. (2006). Children Challenging Industry: All Regions Study of the Effects of Industry-Based Science Activities on the Views of Primary School Children and Their Teachers. New York: Chemical Industry Education Centre: University of York.

Prince, M. J., and Felder, R. M. (2006). Inductive Teaching and Learning Methods: Definitions, Comparisons, and Research Bases. J. Eng. Edu. 95 (2), 123-138. doi:10.1002/j.2168-9830.2006.tb00884.x

Quessada, M.-P., and Clément, P. (2007). An Epistemological Approach to French Syllabi on Human Origins during the 19th and 20th Centuries. Sci. Educ. 16 (910), 991-1006. doi:10.1007/s11191-006-9051-9

Reiss, J., and Sprenger, J. (2017). "Scientific Objectivity," in The Stanford Encyclopedia of Philosophy. Editor E. N. Zalta. Available at: https://plato. stanford.edu (Accessed June 10, 2019).

Rönnebeck, S., Nielsen, J. A., Olley, C., Ropohl, M., and Stables, K. (2018). “The Teaching and Assessment of Inquiry Competences," in Transforming Assessment through an Interplay between Practice, Research and Policy. Editors J. Dolin and R. Evans (Cham: Springer), 27-52. doi:10.1007/978-3319-63248-3_2 
Ropohl, M., Nielsen, J. A., Olley, C., Rönnebeck, S., and Stables, K. (2018). “The Concept of Competence and its Relevance for Science, Technology and Mathematics Education," in Transforming Assessment through an Interplay between Practice, Research and Policy. Editors J. Dolin and R. Evans (Cham: Springer), 3-25. doi:10.1007/978-3-319-63248-3_1

Salout, S. S., Behzadi, M.-H., Shahvarani, A., and Manuchehri, M. (2013). Students' Conception about the Relation of Mathematics to Real-Life. Math. Edu. Trends Res. 2013, 1-7. doi:10.5899/2013/metr-00009

Sandahl, A., and Tøttrup, A. P. (2020). Marine Citizen Science: Recent Developments and Future Recommendations. Cstp 5 (1), 24. doi:10.5334/cstp.270

Scott, I., Fuller, I., and Gaskin, S. (2006). Life without Fieldwork: Some Lecturers' Perceptions of Geography and Environmental Science Fieldwork. J. Geogr. Higher Edu. 30 (1), 161-171. doi:10.1080/03098260500499832

Sheard, J. K., Quistgaard, N., Dunn, R. R., and Tøttrup, A. P. (2018). Citizen Science Engagerer Børn I Naturvidenskab. MONA 2018 (3), 25-40. Available at: https:// tidsskrift.dk/mona/article/view/107171 (Accessed October 6, 2020)

Silfver, E. (2018). Gender Performance in an Out-Of-School Science Context. Cult. Stud. Sci. Educ. 14 (1), 139-155. doi:10.1007/s11422-017-9851-z

Suarez, V. A., and Tsutsui, N. D. (2004). The Value of Museum Collections for Research and Society. BioScience 54 (1), 66-74. doi:10.1641/0006-3568(2004) 054[0066:tvomcf]2.0.co;2
Taasoobshirazi, G., and Carr, M. (2008). A Review and Critique of Context-Based Physics Instruction and Assessment. Educ. Res. Rev. 3 (2), 155-167. doi:10. 1016/j.edurev.2008.01.002

Ulriksen, L. (2009). The Implied Student. Stud. Higher Edu. 34 (5), 517-532. doi:10. 1080/03075070802597135

Xanthoudaki, M. (2015). Museums, Innovative Pedagogies and the Twenty-First Century Learner: a Question of Methodology. Mus. Soc. 13 (2), 247-265. doi:10. 29311/mas.v13i2.329

Conflict of Interest: The authors declare that the research was conducted in the absence of any commercial or financial relationships that could be construed as a potential conflict of interest.

Copyright (c) 2021 Berg, Achiam, Poulsen, Sanderhoff and Tøttrup. This is an openaccess article distributed under the terms of the Creative Commons Attribution License (CC BY). The use, distribution or reproduction in other forums is permitted, provided the original author(s) and the copyright owner(s) are credited and that the original publication in this journal is cited, in accordance with accepted academic practice. No use, distribution or reproduction is permitted which does not comply with these terms. 